\title{
Radiotracer Study of Synergistic Effects of Organophosphorus Compounds on the Extraction of Silver by N-(thio acetyl) benzamide into n-butanol
}

\author{
P. Dey and S. Basu* \\ The Department of Chemistry, the University of Burdwan, Burdwan 713104, India
}

\section{Received: October 12, 2010; In Final Form: December 9, 2010}

The extraction behaviour of $\mathrm{Ag}(\mathrm{I})$ from an aqueous nitrate medium employing (N-thio acetyl) benzamide(HA) in n-butanol has been investigated in presence of several organophosphorus donors like, tri-butyl phosphine oxide, tri-phenyl phosphine oxide and tributyl phosphate at $\mathrm{pH} 4.0$ adopting radio tracer technique. The synergism was found in presence of neutral donors due to the formation of the adduct $\left[\mathrm{Ag}(\mathrm{A})\left(\mathrm{H}_{2} \mathrm{O}\right)(\mathrm{B})\right]$ in n-butanol $(\mathrm{B}$ denotes neutral donor). The overall equilibrium constant for each of the three ternary complexes and also for binary system were calculated from extraction data. It was found that the extent of extraction of $\mathrm{Ag}$ (I) in organic phase both as the binary complex as well as ternary complex increased with increase in temperature. The temperature dependence of the equilibrium constants were investigated in order to evaluate the thermodynamic parameters like enthalpy $\left(\Delta H^{\circ}\right)$, entropy $\left(\Delta S^{\circ}\right)$ and free energy $\left(\Delta G^{\circ}\right)$. Extraction mechanism was finally supported by I.R spectra of ternary adduct.

\section{Introduction}

Silver occurs in small quantities in nature along with coinage metals and is a metal of commercial importance. Inhalation exposure to silver leads to adverse cardiovascular or musculoskeletal effects and respiratory irritation. Acute inhalation of aerosol containing colloidal silver leads to ultra-structural damage and disruption of cell of tracheal epithelium. It also leads to abdominal pain as well as gastrointestinal pain. ${ }^{1-2}$ Because of the above mentioned hazards; there is always a need for a good separation method of $\mathrm{Ag}$ (I) from industrial and photographic wastes. This precious metal is used largely in medicine $^{3}$, the disinfection of water ${ }^{4}$, photography ${ }^{5}$, electronic devices, and cloud seeding. ${ }^{6}$ Silver also enters the environment from industrial waters, because it often occurs as an impurity in copper, zinc, arsenic, and antimony ores. ${ }^{7}$ Bowen $^{8}$ also had suggested that silver might pose a potential risk as a water pollutant because of the lack of recycling of mined silver. Liquidliquid extraction methods are frequently used for the separation and preconcentration of silver. ${ }^{9-12}$ A considerable amount of work has been carried out on solvent extraction of silver with sulfur-containing extractants from nitrate or sulphate media ${ }^{13-21}$, or calixarene derivatives ${ }^{22-24}$ and calixarene analog $\mathrm{s}^{25}$, quaternary amine with chelating ligand HTTA, ${ }^{26}$ as mixed extraction or extraction of $\mathrm{Ag}$ (I) from aqueous nitrate medium with hostguest assemblies involving macrocycles and different carboxylic acids. ${ }^{27-28}$ But only a few attention has been paid on the synergistic effect of phosphine oxides on the extraction of $\mathrm{Ag}$ (I) from aqueous nitrate medium. ${ }^{29}$

In the present investigation, systematic study of synergistic effects of phosphine oxides and tributyl phosphate on the extraction of $\mathrm{Ag}$ (I) from aqueous nitrate medium with $\mathrm{N}$-(thioacetyl) bezamide into $\mathrm{n}$-butanol is being reported. The ligand was synthesized and characterized in our laboratory. Temperature dependence of extraction equilibrium have been studied in order to evaluate the thermodynamic parameters responsible for the extraction. Finally, IR data were used to support the extraction mechanism.

\section{Experimental}

2.1. Reagents and instrument. The chelating ligand $(\mathrm{N}-$ thio acetyl) benzamide was synthesised by the reaction of thioacetamide and benzoylchloride, derived form benzoic acid, which were obtained from Aldrich, USA. The donor reagents used in this work e.g tri-butyl phosphine oxide (TBPO), triphenyl phosphine oxide (TPPO), tri-butyl phosphate (TBP), were also collected from Aldrich; USA. The solvents were purified by standard procedures. All other reagents used were of A.R. grade. A stock solution of silver was prepared by dissolving A.R. $\mathrm{AgNO}_{3}$ in deionized water and a working stock was prepared by appropriate dilution. In order to spike the solution, an appropriate volume of stock solution of $\mathrm{Ag}(\mathrm{I})$ was mixed, with few drops of tracer solution containing, ${ }^{110 \mathrm{~m}} \mathrm{Ag}$ as $\mathrm{AgNO}_{3}$ supplied by BRIT, India and finally made up to the mark. Microanalysis of carbon, hydrogen and nitrogen content of the synthetic ligand were achieved in a Perkin-Elmer 2400 CHNS-O elemental analyzer. Infrared spectra of ligands and adduct complexes were recorded in a Perkin-Elmer FTIR Model RX1 Spectrometer. A systronics model 335 digital pHmeter equipped with a single electrode was used for $\mathrm{pH}$ measurement. A single channel $\gamma$-ray spectrometer coupled with a well-type NaI (T1) detector of Nucleonix, India make was used for radio-activity measurement. The radioisotope ${ }^{110 \mathrm{~m}} \mathrm{Ag}$ was assayed by its $667 \mathrm{kev}$ photopeak. Thermal analyses of extracted species were carried out in a PerkinElmer Diamond TG/DTA analyzer heated from $30^{\circ} \mathrm{C}-750{ }^{\circ} \mathrm{C}$ under $\mathrm{N}_{2}$.

2.2. Extraction procedure. In the general extraction procedure, $5 \mathrm{ml}$ aqueous solution of $\mathrm{AgNO}_{3}$ containing $52 \mu \mathrm{g}$ spiked $\mathrm{Ag}(\mathrm{I})$, and adjusted to a $\mathrm{pH} 4.00$ was extracted with equal volume of $n$-butanol solution of chelating ligand for a period of 30 minutes in a mechanical shaker. Ionic strength of the solution was kept fixed by using $0.50 \mathrm{M} \mathrm{KNO}_{3}$. For synergistic study, organic phase was mixed with appropriate donor reagent of desired concentration. After the equilibration, two phases were separated and radio-activities of equal volumes of both of the two phases were measured. Distribution coefficient (D) were computed from,

*Corresponding author. E-mail: basu_sukalyan@yahoo.co.in 


$$
\mathrm{D}=\frac{\text { Radioactivity in organic phase }}{\text { Radioactivity in aqueous phase }}
$$

Material-balance in the extraction was checked from the counts of two phases separately.

2.3. Synthesis and characterisation of the chelating agent. The chelating ligand was synthesized by the general condensation reaction between benzoyl chloride and thioacetamide (1:1). The starting material, A.R. benzoic acid (2.00 g) was refluxed for $2 \mathrm{~h}$ with successive addition of thionyl chloride. The excess of chlorinating agent was removed by slow evaporation. In a beaker, a saturated solution of thioacetamide $(1.24 \mathrm{~g})$ in double distilled nitrobenzene solvent, free from any water, was prepared. The solvent was purified by drying over calcium oxide followed by distillation before use. This thioacetamide solution was then condensed with benzoyl chloride for $1 \mathrm{~h}$ over a boiling water bath. The brown color precipitate so appeared was separated by filtration process, recrystallized from chloroform solvent and dried. The dried compound melts at (94 \pm $2{ }^{\circ} \mathrm{C}$ ). The proposed formula of the ligand (Scheme 1) is in good agreement with the stoichiometries obtained from their CHN elemental analysis data as well as IR and ${ }^{1} \mathrm{H}$ NMR data. From CHN analysis, Found, \% ; C 60.26, H 4.98, N 7.65 Calculated, \% ; C 60.33, H 5.02, N 7.82. In the IR spectrum of the ligand absence of band at $3760 \mathrm{~cm}^{-1}$ due to $\mathrm{v}_{\mathrm{OH}}$ (present in original acid ) and clear presence of sharp peaks at $1689 \mathrm{~cm}^{-1}$ (due to carbonyl group of acid) ${ }^{30}$ corresponding to support only hydroxyl group of acid take part in condensation reaction. Further observation of $v_{\mathrm{C}=\mathrm{S}}$ at $1175 \mathrm{~cm}^{-1}$ supported the view that the thio group in thioacetamide is not affected in the course of synthesis. 1H NMR data also agrees well, $\delta$, at $7.6 \mathrm{ppm}(5 \mathrm{H}$, Aromatic), methyl proton occur at $2.3 \mathrm{ppm} \delta$ (s $3 \mathrm{H}$, methyl group), Amide proton $-\mathrm{HN}$ - arise at $8.1 \mathrm{ppm} \delta(\mathrm{s}, 1 \mathrm{H} \text {, proton })^{31}$

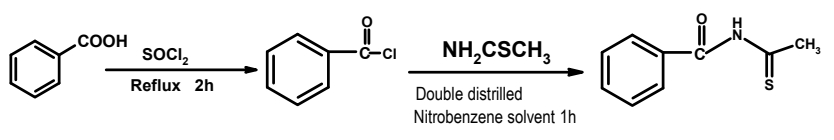

Scheme 1. Synthesis of chelating ligand N-(thio acetyl) benzamide.

\section{Results \& Discussion}

3.1. Effect of equilibration time. Preliminary studies on the extraction of $\mathrm{Ag}$ (I) by $\mathrm{N}$-(thio acetyl) benzamide(HA) in n-butanol show that the two phase reaction is fairly rapid and the equilibrium is reached within 30 minutes. The increase of the time of equilibration does not affect the extraction equilibrium.

3.2. Effect of organic diluents. The effect of organic diluent on the extraction was studied and it was found that maximum extraction was obtained in the case of n- butanol and

TABLE 1: The extraction of Ag (I) with 0.0018 mol.dm $^{-3}$ of $\mathrm{N}$-(thio acetyl) benzamide in different diluent at $\mathbf{p H} 4$

\begin{tabular}{l|c|c}
\hline Diluents & $\mathrm{D}_{0}$ & \% Extraction \\
\hline Carbontetrachloride & 0.135 & 11.89 \\
\hline Chloroform & 0.241 & 19.41 \\
\hline Xylene & 0.341 & 25.42 \\
\hline Toluene & 0.356 & 26.25 \\
\hline Ethylacetate & 0.132 & 11.61 \\
\hline Iso-amyl alcohol & 0.456 & 31.31 \\
\hline n-butanol & 0.689 & 40.79 \\
\hline
\end{tabular}

minimum for Carbontetrachloride. The trend of extraction for organic solvents used follows the order: Carbontetrachloride $<$ Chloroform $<$ Xylene $<$ Toluene $<$ Ethylacetate $<$ iso-amyl alcohol $<$ n-butanol (Table 1.). Butanol being polar solvent allows water molecules in metal coordination sphere and thus, extracts the hydration metal in most.

3.3. Effect of $\mathbf{p H}$ in aqueous phase. Experiments were carried out in different $\mathrm{pH}$ by using 0.014 mol. $\mathrm{dm}^{-3} \mathrm{~N}$ - (thio acetyl) benzamide into n- butanol. At first, it was observed that the percentage of extraction increased with increasing $\mathrm{pH}$ but above $\mathrm{pH} 4.0$, the extent of the extraction decreases. The plot of $\log \mathrm{D}_{\mathrm{o}}$ against $\mathrm{pH}$ resulted in a straight line with slope $\sim 1$ (Figure 1.) indicating that only one $\mathrm{H}^{+}$ion was liberated from HA during the extraction processes. An optimum $\mathrm{pH}$ of 4.0 was selected for the experiments. $\left[\mathrm{D}_{\mathrm{o}}=\right.$ distribution coefficient in presence of only ligand]

3.4. Extraction of $\mathrm{Ag}$ (I) with $\mathrm{N}$-(thio acetyl) benzamide (HA). Extraction of $\mathrm{Ag}$ (I) from nitrate medium was investigated using n-butanol as a diluent. The concentration of ligand was varied from $0.35 \times 10^{-2}$ mol.dm ${ }^{-3}$ to $1.45 \times 10^{-2}$ mol.dm ${ }^{-3}$ in Table 2. The percentage of extraction was found to increase with increase in ligand concentration at fixed $\mathrm{pH}$ 4.0. At higher concentration of ligand, effective stripping of the water molecules take place from the hydrated silver ion sphere by the ligand, rendering the species much more organophilic in nature. The linear plot of $\log \mathrm{D}_{\mathrm{o}}$ against concentration of ligand with a slope $\sim 1$ Figure 2, indicating one molecule of ligand (HA) is involved in the extraction of silver according to equation (1). As the ligand is bidentate in nature, only one molecule of ligand is sufficient to balance the charge of monovalent metal ion.

The overall binary extraction is described as,

$$
\mathrm{Ag}_{\text {aq }}^{+}+[\mathrm{HA}]_{\text {org }}+2 \mathrm{H}_{2} \mathrm{O} \stackrel{\mathrm{k}}{\rightleftarrows}\left[\operatorname{Ag}(\mathrm{A})\left(\mathrm{H}_{2} \mathrm{O}\right)_{2}\right]_{\text {org }}+[\mathrm{H}]^{+}
$$

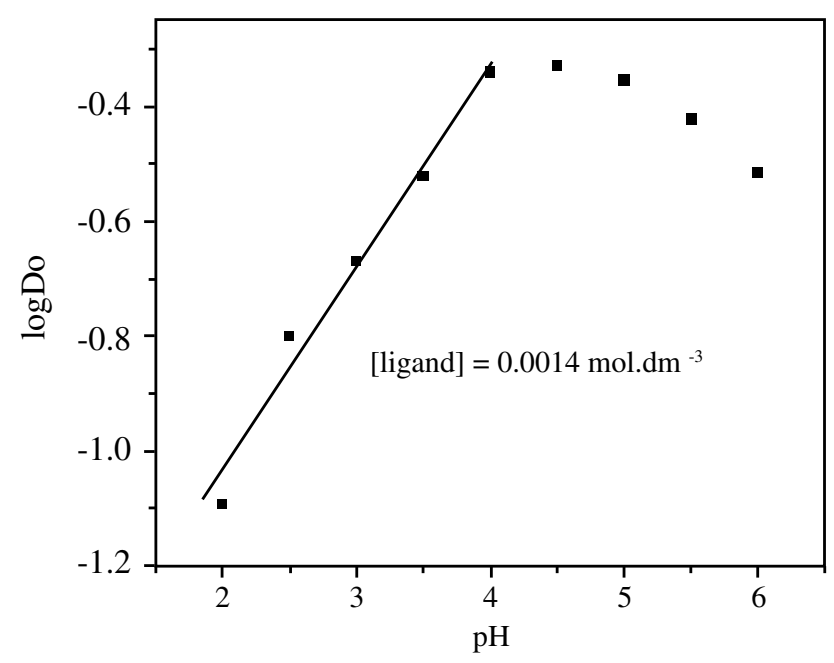

Figure 1. Plot of $\log \mathrm{D}_{0}$ vs $\mathrm{pH}$ for $\mathrm{Ag}(\mathrm{I})$-ligand system in butanol.

TABLE 2: Exaction of $\operatorname{Ag}(\mathrm{I})$ with $\mathrm{N}$-(thio acetyl) benzamide ligand only in butanol at $\mathrm{pH}=4.0$

\begin{tabular}{c|c|c|c}
\hline \multirow{2}{*}{ Ligand } & $\begin{array}{c}\text { Concentration } \\
\text { mol.dm }{ }^{-3} \times 10^{-2}\end{array}$ & $\mathrm{D}_{\mathrm{o}}$ & \% Extraction \\
\hline \multirow{3}{*}{$\begin{array}{l}\text { N-(thio acetyl) } \\
\text { benzamide }\end{array}$} & 0.35 & 0.073 & 4.21 \\
\cline { 2 - 4 } & 0.75 & 0.163 & 14.05 \\
\cline { 2 - 4 } & 1.05 & 0.276 & 21.38 \\
\cline { 2 - 4 } & 1.4 & 0.491 & 29.07 \\
\hline
\end{tabular}




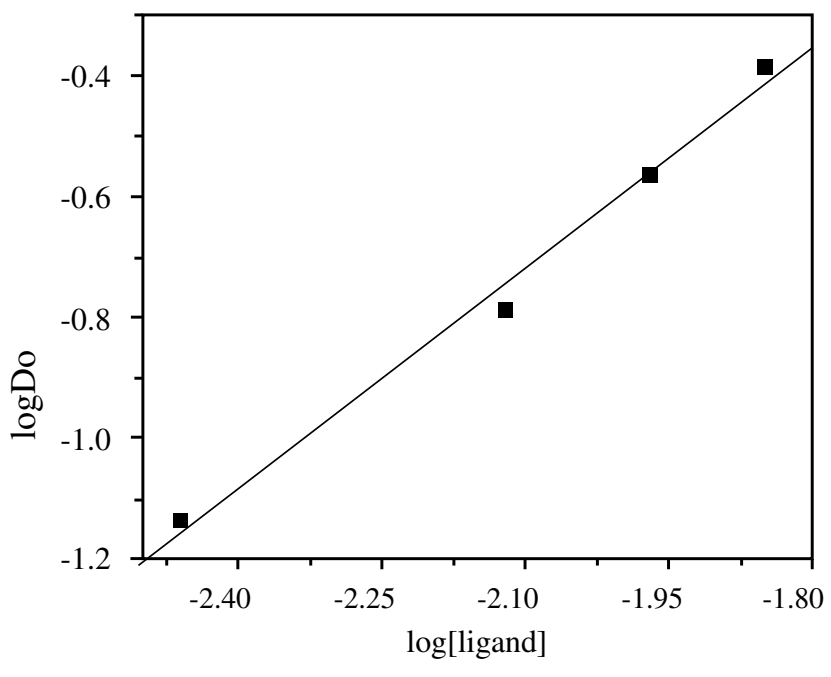

Figure 2. Plot $\log D_{0}$ vs. $\log [\operatorname{ligand}]$ for $A g(I)$ - ligand system.

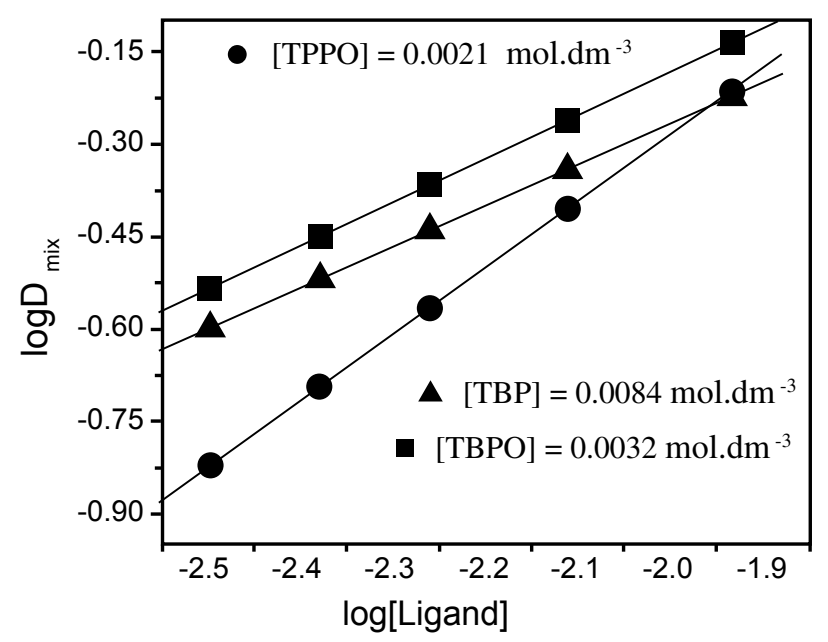

Figure 3. Plot $\log D_{\text {mix }}$ vs $\log$ [ligand] for extraction of $A g(I)-[$ ligand] - donor ternary system at $\mathrm{pH} 4.0$ in butanol keeping [donor] = fixed.

The distribution coefficient is defined by,

$$
D_{0}=\frac{\left[\operatorname{Ag}(\mathbf{A})\left(\mathbf{H}_{2} \mathbf{O}\right)_{2}\right]_{\mathrm{org}}}{\left[\mathrm{Ag}^{+}\right]_{\mathrm{aq}}}
$$

Thus equilibrium constant $(\mathrm{k})$ for binary extraction is related to the distribution coefficient by,

$$
\log \mathrm{k}=\log \mathrm{D}_{\mathrm{O}}-\log [\mathrm{HA}]-\mathbf{p H}
$$

3.5. Synergistic extraction of $\mathrm{Ag}$ (I) complex in presence of phosphine oxide andtributyl phosphate. The distribution ratio of $\mathrm{Ag}$ (I) extracted with HA increases by the addition of different organophosphorous compounds. This is attributed to the formation of a more lipophilic adduct with these donors. In the ternary extraction system, the $\log \mathrm{D}_{\text {mix }}$ vs. $\log [\mathrm{HA}]$ plots at fixed concentration of donor and fixed $\mathrm{pH}$ of aqueous phase yielded slope of $\sim 1$ Figure 3 , while the $\log \mathrm{D}_{\text {mix }}$ vs. $\log$ [donor] plots at fixed concentration of ligand and fixed $\mathrm{pH}$ of aqueous phase showed straight line behavior with a slope also $\sim 1$ in Figure 4. suggesting the composition of the extracted species of the type $\operatorname{Ag}(\mathrm{A})(\mathrm{B})$. The overall reaction of the generally accepted synergistic extraction of silver ions is given by Eq. (4) where one molecule of ligand and one molecule donor (B) are present in the extracted adduct.

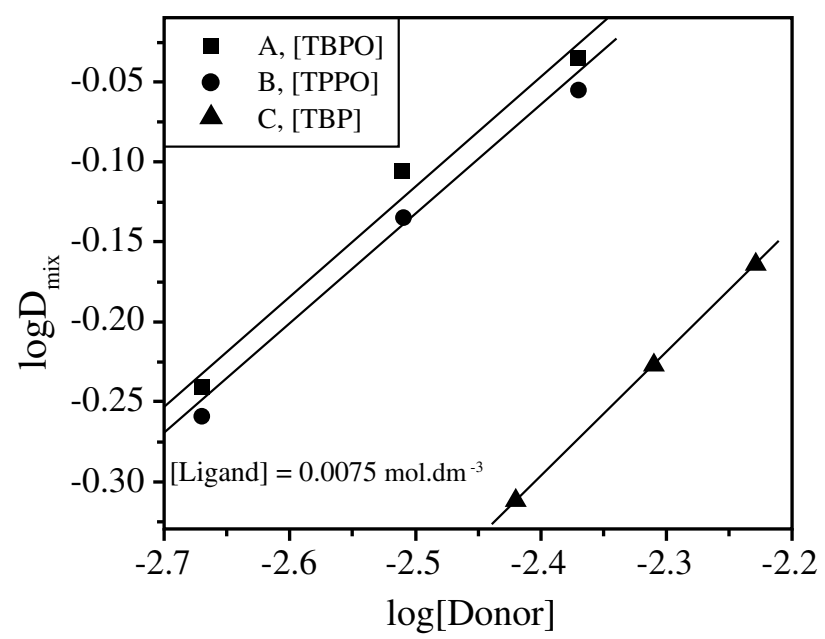

Figure 4. Plot of $\log \mathrm{D}_{\text {mix }}$ vs $\log$ [donor] for extraction of $\operatorname{Ag}(\mathrm{I})$ [ligand]- donor ternary system at $\mathrm{pH} 4.0 \mathrm{in} \mathrm{n-butanol} \mathrm{keeping} \mathrm{[ligand]}$ $=$ fixed.

$$
\begin{aligned}
\mathrm{Ag}_{\text {aq }}^{+}+[\mathrm{HA}]_{\text {org }}+[\mathrm{B}]_{\text {org }}+\mathrm{H}_{2} \mathrm{O} \stackrel{\mathrm{k}}{\rightleftarrows} \\
{\left[\mathrm{Ag}(\mathrm{A})\left(\mathrm{H}_{2} \mathrm{O}\right)(\mathrm{B})\right]_{\text {org }}+[\mathrm{H}]^{+}{ }_{\text {aq }} }
\end{aligned}
$$

Hence, ternary adduct formation may be described as, Obviously, Equilibrium constant $(\mathrm{K})$ is shown by

$$
\begin{gathered}
\mathbf{K}=\frac{\left[\mathbf{A g}(\mathbf{A})\left(\mathbf{H}_{2} \mathbf{O}\right)(\mathbf{B})\right]_{\text {org }}[\mathbf{H}]_{\text {aq }}^{+}}{\left[\mathbf{A g}^{+}\right]_{\text {aq }} \cdot[\mathbf{H A}]_{\text {org. }}[\mathbf{B}]_{\text {org }}} \\
D_{\text {mix }}=\frac{\left[\mathbf{A g}(\mathbf{A})\left(\mathbf{H}_{2} \mathbf{O}\right)(\mathbf{B})\right]_{\text {org }}+\left[\mathbf{A g}(\mathbf{A})\left(\mathbf{H}_{2} \mathbf{O}\right)_{2}\right]_{\text {org }}}{\left[\mathbf{A g}^{+}\right]_{\text {aq }}}
\end{gathered}
$$

But, distribution coefficient $\left(\mathrm{D}_{\text {mix }}\right)$ for mixed extraction is, Combining Eqs. (2), (5) and Eq (6), we get

$$
\mathbf{K}=\frac{\left(\mathbf{D}_{\text {mix }}-\mathbf{D o}\right)[\mathbf{H}]_{\text {aq }}^{+}}{[\mathbf{H A}]_{\mathrm{org}}[\mathbf{B}]_{\mathrm{org}}}
$$

Taking logarithm and rearranging,

$$
\log K=\log \left(D_{\text {mix }}-D_{o}\right)-\log [H A]_{o r g}-\log [B]_{o r g}-p H
$$

Extraction of $\mathrm{Ag}$ (I) with pure donor is negligible under the present condition.

The adduct formation reaction in the organic phase may be represented as

$$
\begin{aligned}
\operatorname{Ag}(A)\left(\mathrm{H}_{2} \mathrm{O}\right)_{2}+ & {[\mathrm{B}]_{\text {org }} \stackrel{\mathrm{K}_{\mathrm{S}}}{\longrightarrow} } \\
& {\left[\operatorname{Ag}(\mathrm{A})\left(\mathrm{H}_{2} \mathrm{O}\right)(\mathrm{B})\right]_{\text {org }}+\mathrm{H}_{2} \mathrm{O} }
\end{aligned}
$$

3.6. Degree of synergism in extraction and equilibrium constant. The degree of synergism can be quantified by synergistic coefficient (SC). It is used to describe enhancement in the equilibrium distribution ratio when two or more extractants are used as a mixture for extraction. $\mathrm{SC}=\log \left[\mathrm{D}_{\text {mix }} /\left(\mathrm{D}_{\mathrm{o}}+\mathrm{D}_{\mathrm{S}}\right)\right]$

Where $D_{\text {mix }}, D_{o}$ and $D_{S}$ denote the distribution ratios of a metal ion with mixture of ligand and donor, pure ligand $(\mathrm{O})$, and only donor (B) respectively. In the present case, $D_{S}=0$, 
TABLE 3: Synergistic extraction of Ag (I) by mixture of chelating ligand and organophosphorus donor. Concentration of ligand $=0.0075$ mol.dm ${ }^{-3}, \mathrm{pH}=4.0$, solvent $=$ n-butanol, $D_{0}=\mathbf{0 . 1 6 3}$,

\begin{tabular}{c|c|c|c|c|c}
\hline Donor & $\begin{array}{c}\text { Conc of donor } \\
\text { mol.dm }^{-3}\end{array}$ & $\mathrm{D}_{\text {mix }}$ & $\begin{array}{c}\% \\
\text { Extraction }\end{array}$ & $\mathrm{SC}$ & $\log \beta$ \\
\hline \multirow{3}{*}{ TBPO } & 0.0021 & 0.573 & 27.16 & 0.590 & 3.075 \\
& 0.0032 & 0.782 & 32.56 & 0.678 & 3.071 \\
& 0.0042 & 0.912 & 47.69 & 0.750 & 3.035 \\
\hline \multirow{3}{*}{ TPPO } & 0.0021 & 0.550 & 25.92 & 0.525 & 3.049 \\
& 0.0031 & 0.761 & 31.57 & 0.666 & 3.069 \\
& 0.0041 & 0.881 & 46.84 & 0.730 & 3.027 \\
\hline \multirow{3}{*}{ TBP } & 0.0038 & 0.487 & 32.75 & 0.472 & 2.715 \\
& 0.0048 & 0.592 & 37.18 & 0.557 & 2.735 \\
& 0.0059 & 0.686 & 40.68 & 0.621 & 2.731 \\
\hline
\end{tabular}

Where, $\mathrm{SC}=$ Synergistic coefficient $=\log \mathrm{D}_{\text {mix }} /\left(\mathrm{D}_{0}\right)$ and $\beta$ $\left(\mathrm{mol}^{-1}\right)=\left(\mathrm{D}_{\text {mix }}-\mathrm{D}_{\mathrm{o}}\right) / \mathrm{D}_{\mathrm{o}}[\mathrm{B}]$, apparent formation constant $\mathrm{B}=$ Donor

TABLE 4: Equilibrium constants for binary and ternary system

\begin{tabular}{c|c|c|c|c}
\hline \multicolumn{2}{c|}{ Binary system } & \multicolumn{3}{c}{ Ternary System } \\
\hline System & $\operatorname{logk}$ & Donor & $\operatorname{logK}$ & $\log \mathrm{K}_{\mathrm{S}}$ \\
\hline \multirow{3}{*}{$\operatorname{Ag}(\mathrm{I})$-ligand } & \multirow{3}{*}{-2.62} & TBPO & 0.403 & 3.023 \\
& & TPPO & 0.378 & 2.998 \\
& & TBP & 0.051 & 2.671 \\
\hline
\end{tabular}

The apparent stability constant $(\beta)$ is given by: $\beta=\left(D_{\text {mix }}-D_{0}\right)$ / $\mathrm{D}_{\mathrm{o}}[\mathrm{B}]$

Synergism was observed at all the compositions studied. Keeping the concentration of ligand constant it was observed that the synergistic coefficient increased with an increase in the concentration of the synergist, organophosphorus extractant Table 3, at fixed $\mathrm{pH}$ of the aqueous phase. The trend in $\mathrm{SC}$ and $\beta$-value shown in Table 3 , for organophosphors donors taken up here follow the order: TBPO $>$ TPPO $>$ TBP keeping parity with their electron donor abilities. Thus, TBP having much poor donor ability with respect to two phosphine oxides results only low values of stability constant in compare to TBPO and TPPO Again If we compare the $\operatorname{logK}$ (ternary equilibrium constant) and $\log \mathrm{K}_{\mathrm{S}}$ (adduct formation equilibrium constant) values Table 4 , it is observed that the above two parameters are found to be highest in case of tri-butyl phosphine oxide (TBPO). The $\log \mathrm{K}_{\mathrm{S}}$ values clearly show that TBPO is the most effective synergistic agent among the three organophosphorus donors used in present investigation. This trend can be correlated with the relative basic natures of the oxophosphorus donors. Somewhat similar trend was observed in the synergistic extraction of other transition metals and actinides. ${ }^{32-34}$ Overall enhancement effects of organophosphorus compounds are found to be very high. The liquid-liquid extraction of a metal ion with a chelating agent is essentially determined by the stability and extractability of uncharged metal complex e.g. $\left[\mathrm{Ag}(\mathrm{A})\left(\mathrm{H}_{2} \mathrm{O}\right)(\mathrm{B})\right]$ in present case. Stability of ternary adduct reported in present work is found to be much higher than corresponding organophosphorus adduct of EHPNA complexes of lanthanides ${ }^{35}$ or salicyldyl complexes of $\mathrm{Zr}(\mathrm{IV}) .^{36}$ Presence of soft ligand for a soft metal like silver maybe responsible for higher stability of adducts and addition of phosphine oxide donors on such system accelerates the degree of extraction into nonpolar solvent.

3.7. Extraction mechanism and thermodynamic parameters. Aqueous solution of silver ion exist as $\mathrm{Ag}\left(\mathrm{H}_{2} \mathrm{O}\right)_{4}{ }^{+}$i.e. tetra coordinated silver ion with two molecule of water held firmly and two loosely bound molecules of water ${ }^{37}$, due to the

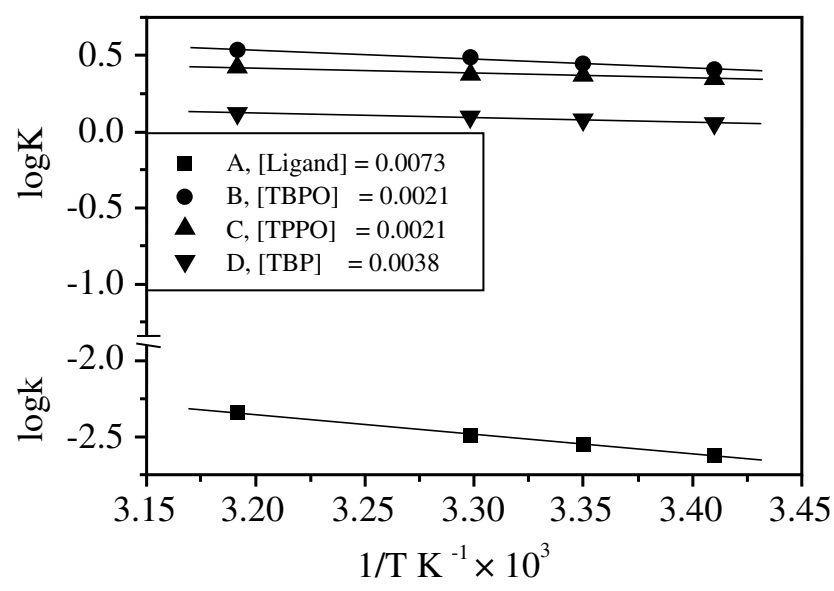

Figure 5. Temperature variation plot of equilibrium constant of binary and ternary systems. The line 'A' only presence of ligand, and 'B', 'C', 'D' lines are the synergistic mixture of different donor presence of fixed ligand concentration. Exact concentration of donors and ligand in mol.dm ${ }^{-3}$ are shown in the figure.

TABLE 5: Thermodynamic parameters related to binary and ternary extraction system

\begin{tabular}{l|r|c|c}
\hline \multicolumn{1}{c|}{ System } & $\begin{array}{c}\Delta H^{\circ} \\
\left(\mathrm{kJ} \cdot \mathrm{mol}^{-1}\right)\end{array}$ & $\begin{array}{c}\Delta S^{\circ} \\
\left(\mathrm{JK}^{-1} \cdot \mathrm{mol}^{-1}\right)\end{array}$ & $\begin{array}{c}\Delta G^{\circ} \\
\left(\mathrm{kJ} \cdot \mathrm{mol}^{-1}\right) \\
\text { at } 27^{\circ} \mathrm{C}\end{array}$ \\
\hline $\mathrm{Ag}(\mathrm{I})$-Ligand & $23.62 \pm 0.2$ & $29.56 \pm 0.5$ & $14.81 \pm 0.1$ \\
$\mathrm{Ag}(\mathrm{I})$-Ligand-TBPO & $10.13 \pm 0.1$ & $42.44 \pm 0.1$ & $-2.61 \pm 0.4$ \\
$\mathrm{Ag}(\mathrm{I})$-Ligand-TPPO & $7.62 \pm 0.2$ & $33.27 \pm 0.3$ & $-2.36 \pm 0.2$ \\
$\mathrm{Ag}(\mathrm{I})$-Ligand-TBP & $5.32 \pm 0.3$ & $21.47 \pm 0.2$ & $-1.12 \pm 0.2$ \\
\hline
\end{tabular}

fact that silver ion is a soft metal and water molecules are hard in nature. ${ }^{38}$ HSAB theory also confirms that, the selective ligand containing $\mathrm{N}$ or $\mathrm{S}$ donor atoms interact strongly with soft acids like $\operatorname{Ag}(\mathrm{I})$ even in the presence of high concentration of protons and loosely bound water molecule are released from co-ordinated sphere.

The equilibrium extraction constants $\log \mathrm{k}$ and $\log \mathrm{K}$ for the studied complexes were obtained from the equilibrium metal concentration in the organic and aqueous phase using Eqs. (3) and (8). From the values of equilibrium extraction constant at the temperature range investigated, enthalpy changes were calculated using the Vant's Hoff equation. ${ }^{39}$

$$
\log K=-\frac{\Delta H^{\circ}}{2.303 R T}+\frac{\Delta S^{\circ}}{2.303 R}
$$

The plot of $\log \mathrm{K}$ against $1 / \mathrm{T}$ Figure 5 is a straight line where the slope gives the enthalpy of reaction $\left(\Delta H^{\circ}\right)$ and intercept corresponds to entropy $\left(\Delta S^{\circ}\right)$ value and these data were used to obtain the corresponding free energy changes. The results are summarized in Table 5. The thermodynamic data can be explained on the basis of two factors associated with the process of extraction e.g, 1) The dehydration of the metal cation and the hydration of the released protons, 2) The combination of metal cation and ligand anion in the organic phase and the simultaneous deprotonation of the formed chelates. ${ }^{40}$ Concerning the enhanced entropy contribution, the literature data $^{41}$ in similar cases show that the degree of order which is lost during the dehydration of the cation is not compensated by the order caused by the hydration of the proton. Again, it is well-known that for inner-sphere complexes the entropy term is favored and the enthalpy term is disfavored i.e.,. ${ }^{42}$ In such com- 


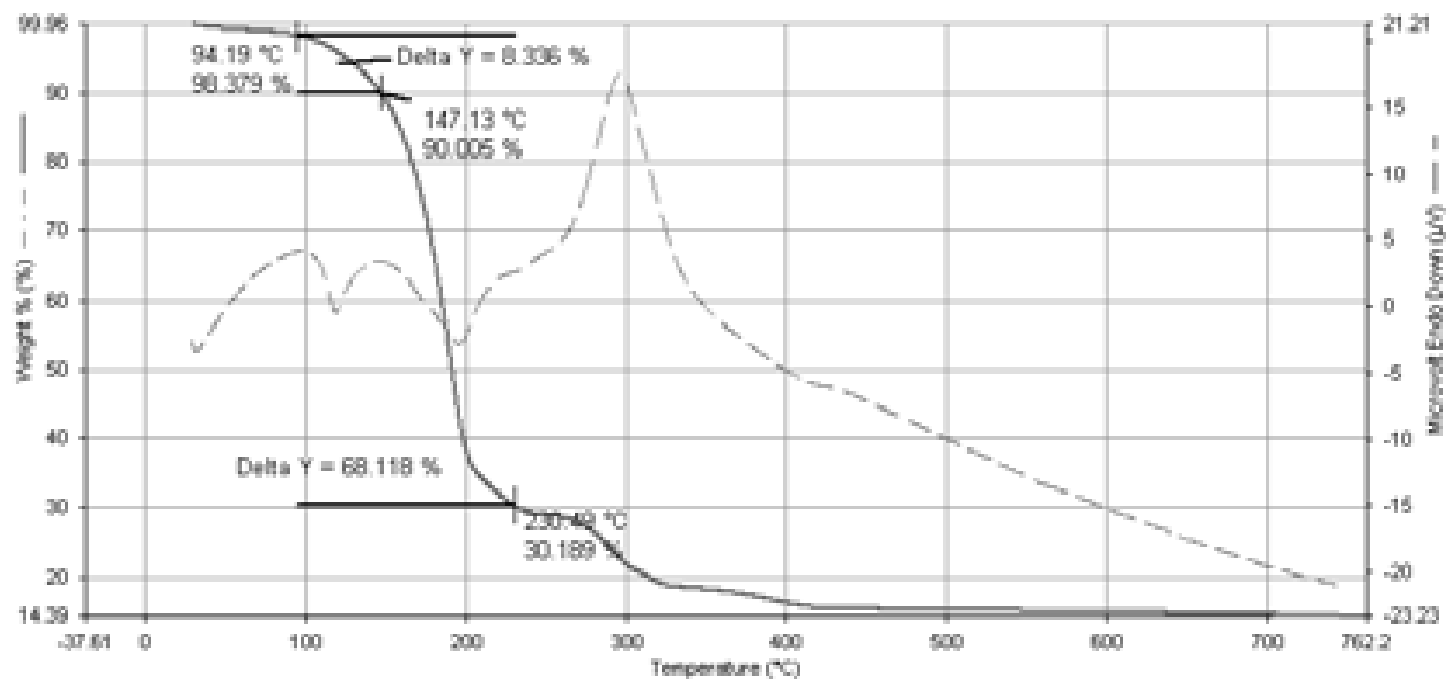

Figure 6A. Thermal plot of binary extracted complex.

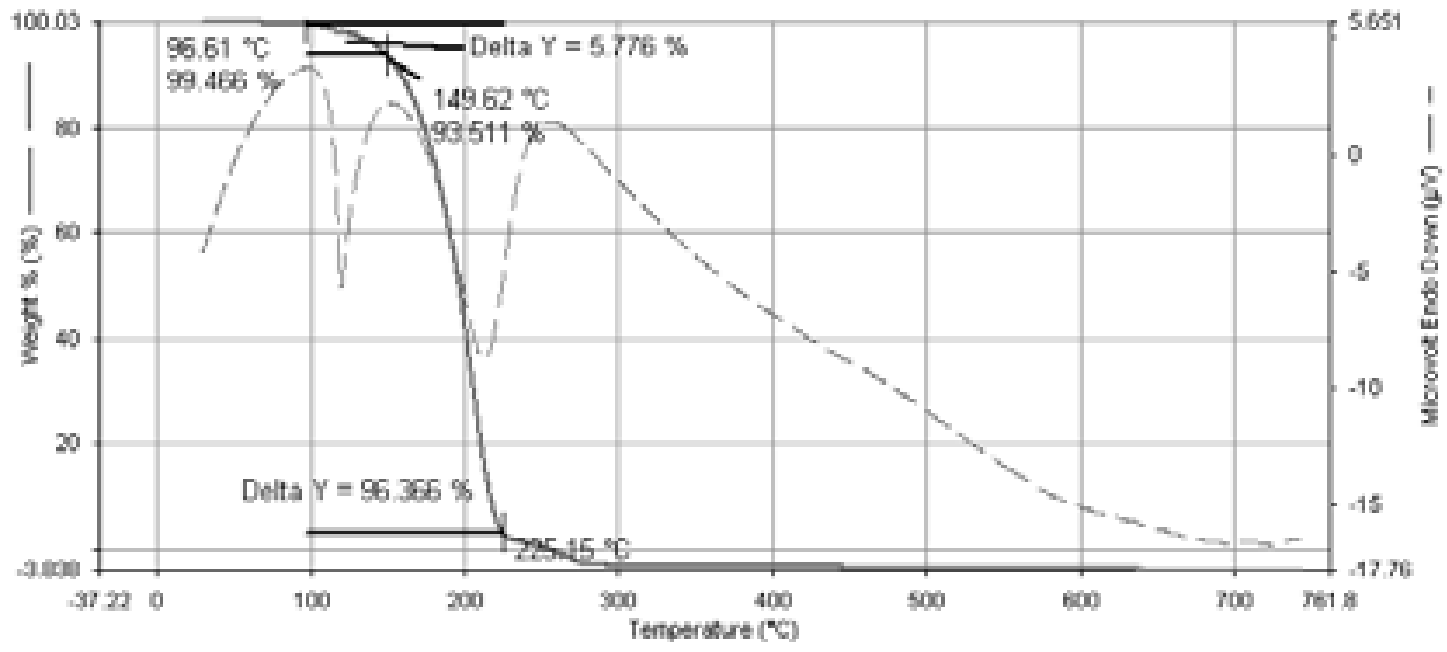

Figure 6B. Thermal plot of ternary extracted complex.

plexes the hydrated sphere is disrupted more extensively and the net entropy and enthalpy changes are positive. On the other hand the lower values of $\left(\Delta H^{\circ}\right)$ of adduct than single extraction of metal, is indicative of relatively smaller heat effects involved in the formation of the extracted complex. It is interesting to find that the enthalpy change of the synergistic extraction process is relatively small in the experimental temperature range. From these values it is clear that the adduct complex formation reaction proceeds spontaneously in the forward direction, with relatively high entropy gain than binary complex at the standard state conditions. This maximum entropy gain is explained by the extensive disruption of the hydration sphere when adduct is formed and hence net disorder of the system which contributes to increase positive $\Delta S^{\circ}$ change as a feature of the innersphere complexes. Therefore synergistic effect of neutral donor is explained by the replacement the co-ordinated water molecule from primary co-ordination sphere of the metal.

3.8. Infrared spectroscopy. The infra-red spectrum of the extracted compound was recorded after evaporating the solvent. From spectral data, it was observed that the $v_{\mathrm{C}=\mathrm{S}}$ band was shifted from $1175 \mathrm{~cm}^{-1}$ in free ligand to $1125 \mathrm{~cm}^{-1}$ in the extracted complex. ${ }^{30}$ This indicated coordination took place through 'S'. Silver being soft metal prefers to bond soft centre 'sulfur' atom in ligand. Hence $v_{\mathrm{C}=\mathrm{S}}$ frequency was shifted to down field. Instead, new absorption bands appear at $1556 \mathrm{~cm}^{-1}$, which was assigned to the $\mathrm{C}=\mathrm{N}$ stretching vibrations. This implies that the complexes incorporate deprotonated ligands. ${ }^{43}$ Similarly the $v_{\mathrm{P}=\mathrm{O}}$ band has been shifted from $1144 \mathrm{~cm}^{-1}$ in free phosphine oxide donor to $1115 \mathrm{~cm}^{-1}$ which characterize the $\mathrm{P}=\mathrm{O}-\mathrm{Ag}$ bond in adduct complex. Presence of water molecules in both binary and ternary extracted species ware indicated by a band at $3455 \mathrm{~cm}^{-1}$ and at $1384 \mathrm{~cm}^{-1}$.

3.9. Thermal analysis of extracted complexes. $\mathrm{Ag}$ (I) is generally know to form 2-coordinates and 4-coordinates complexes but with ligands having $\pi$ - bonding ability tetra-coordinate complex predominate. ${ }^{44}$ Hence, in binary extract complexation with HA having $\pi$ - acid character, two cites are occupied by bidenate HA while two other sites are filled by water molecules in order to keep electroneutrality. In presence of donor (B), one water molecule is replace by donor in ternary complex. Presence of water molecules in binary and ternary complexes were indicated by IR data. Number of water molecules was confirmed by thermal analysis of extracted complexes which were evaporated to remove the solvent. Both TG and DTA data were recorded between $30{ }^{\circ} \mathrm{C}$ to $750{ }^{\circ} \mathrm{C}$ in a static atmosphere of $\mathrm{N}_{2}$ (Figure $6 \mathrm{~A} \& 6 \mathrm{~B}$ ). Results clearly show a loss in weight which nearly corresponds to two molecule of water in binary system and one molecule of water by ternary complex. Loss of water was $8.36 \%$ against a theoretical value $11.07 \%$ in binary complex while it was $5.77 \%$ against theoretical value $3.5 \%$ in mixed adduct in a temperature range above $100{ }^{\circ} \mathrm{C}$. If there would not be any water molecule present in batter case, there would not be any loss in weight in this temperature range. 


\section{Conclusion.}

Bidentate chelating agent used in this work has fair degree of extractability for silver from aqueous nitrate medium. Extraction is further enhanced by the addition of organophosphorus donors which enter into the inner-sphere of metal complex by the dehydration. Applications of such ligand may be of research interest for the solvent extraction of other soft metal ions.

\section{Acknowledgement.}

One of the authors (P. Dey ) acknowledges CSIR for providing him a fellowship. Authors also thank Dr.(Mrs) S. Bhattacharyya (R.R.R. College, W.B, India) for her interest in the present work.

\section{References}

(1) A. Moss and S. Kon, J. Occup. Med. 21, (1979).

(2) S. K. Tandon, M. Chatterjee, A. Bhargava, V. Shukla, and V. Bihari, The Science of the Total Environment. 281, 177 (2001).

(3) I. Kojimia and A. Takayanagi, J. Anal. Atom. Spectrom 11, 213 (1996).

(4) F. X. Abad, R. M. Pinto, J. M. Diez, and A Bosch, Appl. Environ. Microb. 60, 2377 (1994).

(5) K. Chiba, I. Inamoto, and M. J. Saelei, J. Anal. At. Spectrom. 7, 115 (1992).

(6) M. Grajson, Kirk-Othemer Encyclopedia of Chemical Technology, 3rd ed.: Wiley, New York. (1980).

(7) R. Soager, Metallic Row Materials Dictionary, Bank Tobed, Zurich (1984).

(8) H. J. M. Bowen, Trace Element Biochemistry. Academic press, London. (1966).

(9) P. R. Chandrasekhar and B.Rangamannar, J. Radioanal. Nucl. Chem. 214, 159 (1996).

(10) A. Mendes and Z. R. Turel, J. Radioanal. Nucl. Chem. 96, 343 (1985).

(11) Y. Ohmiya, N. T. K. Durg and T Sekine, Bull. Chem. Soc. Jpn. 70, 1167 (1997).

(12) I. M. Kolthoff, M. K. Chantooni and W. Wang, J. Chem. Eng. Data. 38, 556 (1993).

(13) Y. Baba, Y. Umezaki and K. Inoue, J. Chem. Eng. Jpn. 19, 27 (1986).

(14)F. Dietze, K. Gloe, R. Jacobi, P. Muehl, J. Beger, M. Petrich, L. Beyer and E. Hoyer, Solvent Extr. Ion Exch. 7, 223 (1989).

(15) A. Ohki and M. Takagi, Anal. Chim. Acta, 159, 245 (1984).

(16) Y. Baba and K. Inoue, Solvent Extr. Ion Exch. 2, 579 (1984).

(17) K. C. Sole, T. L. Ferguson, and J. B. Hiskey, Solvent Extr. Ion Exch. 12, 1033 (1994).

(18) M. P. Mikhailova and V. A. Mikhailov, Zb. Neorg. Khim, 28, 499 (1983).

(19) K. C. Sole, T. L. Ferguson, and J. B. Hiskey, Solvent Extr.
Ion Exch. 12, 1033 (1994).

(20) V. Stankovic, L. Outarra, F. Zonnevijlle, and C. Comninellis, Sep. Purif. Technol. 61, 366 (2008).

(21) K. Ohtoa, E. Murakami, T. Shinohara, K. Shiratsuch, K. Inoue, and M. Iwasaki, Anal. Chim. Acta. 341, 275 (1997).

(22) T. Nagasaki and S. Shinkai, Bull. Chem. Sot. Jpn. 65, 471 (1992).

(23) R. Perrin, R. Lamartine, and M. Perrin, Pure Appl. Chem. 65, 1549 (1993).

(24) A. Ikeda and S. Shinkai. J. Am. Chem. Soc 116, 3102 (1994).

(25) Y. Okada, F. Ishii, and Y. Kasai, J. Tetrahedron Lett. 34, 1971 (1993)

(26) Y. Ohmiya and T. Sekine, Anal. Sci. 12, 249 (1996).

(27) Y. Dong, S. Farquhar, K. Gloe, L. F. Lindoy, B. R. Rumbel, P. Turner, and K. Wichmann, Dalton Trans. 1558 (2003).

(28) G. Vesna, G. Karsten, F. L. Leonard, and S. M. Myrna, Dalton Trans. 3829 (2004).

(29) H. Yuko, K. Suzuki, and S. Tatsuya, Chem. Lett. 10, 1075 (1981).

(30) K. Nakamoto, Infrared and Raman spectra of inorganic and coordination Compounds, 4th Edn John Wiley \& Sons, NY. (1986).

(31)R. M. Silverstei, G. C. Bassler, and T. C. Marrill, Spectrometric identification of organic Compounds, $4^{\text {th }}$ edn John Wiley, NY. (1963).

(32) S. Banerjee and S. Basu, J. Radioanal. Nucl. Chem. 242, 253 (1999).

(33) S. Banerjee, S. Biswas, and S. Basu, J. Radioanal. Nucl. Chem. 250, 399 (2001).

(34) J. K. Reddy, K. J. Rajesh, and V. A. Reddy, Solvent Extr. Ion Exch. 24, 419 (2006).

(35) B.V. Reddy, L. K. Reddy, A. S. Reddy, M. L. P. Reddy, S. Sujatha, T. R. Rammohan, and A. D. Damodaran, J. Radioanal. Nucl. Chem. 178, 199 (1994).

(36) S. Banerjee and S. Basu, J. Radioanal. Nucl. Chem. 262, 773 (2004).

(37) H. Ohtaki and T. Radnal, Chem. Rev. 93, 1157 (1993).

(38)F.A. Cotton, G. Wilkinson, C. A. Murillo, and M. Bochmann, Advanced Inorganic Chemistry 6th Edn willey, NewYork. (1999).

(39) B. G. Segal, Chemistry Experiment and Theory, 2nd Ed, John Wiley \& Sons, New York p.627, (1989).

(40) G. A. Choppin and A. Morgenstern, Solvent Extr. Ion Exch. 18, 1029 (2000).

(41) K.C. Manke, Electrolytic Dissociation, Academic Press, New York (1961).

(42) A. Ramadan, Mixed Complexes of Some Actinide Elements, M.Sc. Thesis, Ain Shams University, Cairo, Egypt, (1979).

(43) M. A. Abd El-Ghaffar, Z. H. Abdel-Wahab, and K. Z. Elwakeel, Hydrometallurgy 96, 27 (2009).

(44) N.N. Greenwood and A. Earnshaw, Chemistry of the elements (Maxwell MacMillan International Editions) pp.1388-1399. 